\title{
Skeletal morbidity in acute lymphoblastic leukemia of childhood: Effects on bone metabolism
}

\author{
Karen Mandel ${ }^{1}$, Stephanie A. Atkinson ${ }^{2}$, Ronald D. Barr ${ }^{2}$, Paul Pencharz ${ }^{3}$ \\ 1. Department of Pediatrics, Children's Hospital of Eastern Ontario, Ottawa, Ontario, Canada. 2. Department of Pediatrics,
} McMaster University, Hamilton, Ontario, Canada. 3. Research Institute, Hospital for Sick Children, Toronto, Canada.

Correspondence: Karen Mandel. Address: 2630-401 Smyth Road, Ottawa, ON, K1H 8L1, Canada.

Email: kmandel@cheo.on.ca

Received: April 19, 2013

DOI : $10.5430 /$ jhm.v3n1p35

Online Published: May 22, 2013

Accepted: May 5, 2013

URL: http://dx.doi.org/10.5430/jhm.v3n1p35

\begin{abstract}
Background: We have previously shown that the majority of survivors treated for acute lymphoblastic leukemia (ALL) in childhood recovered their bone mineral density (BMD) despite disease effects and prolonged therapy with steroids and methotrexate. However, for a subset of patients who received higher total doses of methotrexate or prednisone, bone mass remained sub-optimal. This study's objective was to determine whether altered bone turnover was reflected in profiles of bone biomarkers as a cause of their persistently reduced bone mass.

Methods: Markers of bone metabolism were measured in 31 survivors of ALL with low BMD. The results were compared to 29 ALL survivors with normal BMD that were matched for gender, age and years since diagnosis. Blood samples obtained at the time of the scan by dual energy x-ray absorptiometry for BMD measure were assayed for 25-hydroxyvitamin D, parathyroid hormone (PTH), and serum CrossLaps.

Results: No difference was found between survivors with low BMD and those with normal BMD for serum 25-OH Vitamin D, PTH or serum C-terminal telopeptide of type-1 collagen (CrossLaps). Vitamin D status was lower than accepted for normal bone health in $37 \%$ of subjects and $27 \%$ of controls.

Conclusion: Survivors of childhood ALL as a whole recover normal BMD. Those that have low BMD after treatments do not have evidence of any permanent alterations in markers of bone turnover. Thus, survivors of childhood ALL who have low BMD likely do so for the same reasons as the general population, such as inadequate Vitamin D status.
\end{abstract}

\section{Key words}

Childhood, Skeletal morbidity, Acute lymphoblastic leukemia, Bone metabolism, Late effects

\section{I ntroduction}

The late effects of cancer therapy are increasingly being recognized as a significant health issue. Acute lymphoblastic leukemia (ALL), the most common malignancy in children, has an overall long-term survival of at least $80 \%{ }^{[1,2]}$. As both the incidence of cancer diagnosis and cure rates continue to rise secondary effects of cancer therapy may impinge on quality of life of the survivors and health care costs. 
The loss of bone mineral mass in ALL has been well documented ${ }^{[3-5]}$. However, low bone mineral density (BMD) is only relevant if it persists in the long term so survivors do not achieve a normal peak bone mass by adulthood as seen in healthy populations. We conducted a large long-term follow-up study of patients who were treated for ALL as children to determine if they were at risk for low BMD in the long term ${ }^{[6]}$.

We have previously published that no difference in BMD was observed for ALL survivors versus age matched normal controls ${ }^{[6]}$. When data were analyzed by age at diagnosis (AAD), and gender, no differences existed between the study group and age-matched normal controls. When analyzing for specific treatment factors, subjects who received very high dose methotrexate (MTX) or higher dose steroids had the greatest proportion of subjects with low femoral BMD but no treatment factors were associated with lower lumbar spine density ${ }^{[6]}$.

The average age at diagnosis of ALL is 4 years of age and therapy is completed 2 to 3 years later, in most instances before the start of puberty. As a proportion of body composition, bone mineral mass remains constant during childhood but increases almost three fold during puberty ${ }^{[7]}$, to achieve peak bone mass in early adulthood ${ }^{[8-10]}$. Unless cancer or cancer therapy causes permanent damage to the neurohormonal mechanisms of children with ALL, patients should resume their normal bone mineralization after successful completion of therapy. The objective of this analysis was to compare the profiles of biochemical markers of bone mineral metabolism between survivors with low BMD compared to matched controls with normal BMD to determine if there are permanent pathophysiologic effects possibly associated with a lower BMD in this sub-population of survivors.

\section{Methods}

\subsection{Study design}

One hundred and six disease free survivors of ALL (62 females and 44 males), who were more than two years from the end of treatment, were recruited into the first part of this study in order to measure their whole body bone mass. Their results were compared to normal age-matched controls; a full description of the study design has been published ${ }^{[6]}$. For the subset of survivors of ALL who had reduced bone density, we then evaluated key biomarkers of bone status.

\subsection{Patients}

Low bone density, a Z-score $<1.0$ below normal reference values for age and gender, was identified in 33 patients but two subjects refused to provide blood samples leaving 31 eligible patients for evaluation. Thirty-one patient survivors of ALL with low BMD of the spine, femur or both were matched by age, gender and years since diagnosis to 29 patient survivors of ALL who had been identified to have normal BMD. As there was not always an acceptable match for each case, some controls matched to more than one case giving 29 controls available for evaluation

\subsection{Biomarkers measured}

Blood samples were obtained when the patients were initially studied for bone mass, spun to obtain plasma which was frozen and stored for this analysis. The plasma was used to measure 25-hydroxyvitamin D (25-OHD) and parathyroid hormone (PTH) as indicators of vitamin D status, osteocalcin as a marker of bone turnover and crosslaps as a measure of bone resorption.

Approximately $8 \mathrm{~mL}$ of blood sample was collected and centrifuged at $3500 \mathrm{rpm}$ at $4^{\circ} \mathrm{C}$ and stored at $-20^{\circ} \mathrm{C}$ until the time of analysis. For each biomarker, all samples were analyzed at the same time to avoid variations between kits. Plasma 25-OHD was measured by RIA (Diasorin, Stillwater, MN) with an intra-assay CV of 5.5\%. C-terminal telopeptide of type-1 collagen (serum CrossLaps or CTx) was measured as serum CTx by enzyme linked immune sorbent assay (ELISA) (Immuno Diagnostic Systems, Fountain Hills, AZ) with an intra-assay CV of 24.5\%. PTH was measured by radioimmunoassay (RIA) 
(DSL Diagnostic Systems, Webster, TX). Serum osteocalcin was measured by enzyme-linked immunosorbent assay (ELISA) (ALPCO Diagnostics, Salem, NH) with an intra-assay coefficient of variation (CV) of $4.6 \%$. However, the results are not reported as the values obtained were very low presumably due to degradation of the osteocalcin due to the samples having been thawed at least once previously.

\subsection{Statistical analysis}

Descriptive statistics included means and ranges for cases and controls. As the data appeared to be normally distributed, analysis was carried out using unpaired T tests and correlation analysis. The statistical analysis was performed using the SAS (Version 9, Cary, North Carolina, USA) software package. Significance was set at $p<0.05$.

\section{Results}

\subsection{Patient characteristics}

There were no significant differences between cases and controls for age at study, age at diagnosis and years since diagnosis (see Table 1). The cases had 22 patients treated with the more intensive protocol versus 20 in the controls. Both groups had 17 patients who received cranial radiation. However, the cases had 6 patients who received very high dose methotrexate (greater than $50 \mathrm{~g} / \mathrm{m}^{2}$ ) versus 3 in the control group. 9 of 43 males studied were between 20-30 years of age and would have achieved peak adult bone mass. 5 of them had low bone density. There were 12 of 62 females in that age group and 5 of them had low bone density.

Table 1. Characteristics of study population

\begin{tabular}{llllll}
\hline & \multicolumn{2}{c}{ Cases } & & \multicolumn{2}{c}{ Controls } \\
\cline { 2 - 3 } \cline { 5 - 6 } & Range & Median & & Range & Median \\
\hline $\begin{array}{lllll}\text { Age at diagnosis } \\
\text { (years) }\end{array}$ & $1.0-16.0$ & 6.5 & $1.3-16.8$ & 6.3 \\
Age at study (years) & $9.3-28.5$ & 16.7 & $8.1-30.6$ & 16.9 \\
Years off treatment & $3.4-11.4$ & 7.2 & & $2.7-11.4$ & 7.6 \\
Gender & Male: 11 & Female: 20 & & Male: 11 & Female: 18 \\
\hline
\end{tabular}

\subsection{Biomarkers}

Vitamin D status: Mean plasma 25-OHD was not different between low and normal BMD groups. Vitamin D deficiency (defined as plasma $25 \mathrm{OHD}<27.5 \mathrm{nmol} / \mathrm{L}$ in the Canadian Health Measures Survey) ${ }^{[11]}$ occurred in $17 \%$ of both the low and normal BMD groups. Using serum $25 \mathrm{OHD}$ of $<40 \mathrm{nmol} / \mathrm{L}$ as the cut-off below which is considered inadequate for bone health ${ }^{[11]}, 37 \%$ of cases and $27 \%$ of controls would qualify. There was no effect of season found on Vitamin D status with a mean of 64.5 versus $62.2 \mathrm{nmo} / \mathrm{L}$ for summer and winter, respectively. Vitamin D status was not significantly correlated with low BMD of the spine $(p=0.056)$ nor the femur $(p=0.99)$.

Parathyroid Hormone: There was no significant difference in PTH concentration between the low and normal BMD groups. No correlation existed between PTH and Vitamin D status.

Crosslaps: Serum CTx did not differ between the low and normal BMD groups.

Table 2 summarizes the results of the biomarker assays. 
Table 2. Bone biomarkers in cases compared to matched controls

\begin{tabular}{|c|c|c|c|c|c|c|}
\hline & \multicolumn{3}{|c|}{ Cases } & \multicolumn{3}{|c|}{ Controls } \\
\hline & Range & Mean & SD & Range & Mean & SD \\
\hline Vitamin D (nmol/L) & $14.2-167.4$ & 61.4 & 38.3 & $0.9-194.1$ & 66.0 & 41.7 \\
\hline $\begin{array}{l}\text { Parathyroid hormone } \\
\text { (pmol/L) }\end{array}$ & $0.97-7.75$ & 3.76 & 1.4 & $1.02-7.78$ & 3.85 & 1.86 \\
\hline Crosslaps (nmol/L) & $482.3-1614.0$ & 882.7 & 238.2 & $576.1-1835.1$ & 877.9 & 243.7 \\
\hline
\end{tabular}

\section{Discussion}

Many studies have demonstrated abnormalities of BMD and bone mineral metabolism in children with ALL at diagnosis, as well as during and at the completion of chemotherapy ${ }^{[12-18]}$. This report highlights the fact that normal bone turnover appears to recover in survivors of ALL, even in those who were exposed to the more intensive chemotherapy. Although bone density in most patients returned to normal when assessed more than two years after treatment, any deficits in bone may be attributed to sub-optimal bone accretion during the post-pubertal period rather than ongoing perturbations in bone turnover. If asymptomatic, having low bone mass for gender and age during or at the end of treatment is insignificant as long as survivors of ALL achieve their normal adult peak bone mass.

Many factors have been shown to result in lower bone mass after treatment for ALL. These include cranial radiation, growth hormone deficiency, reduced body size, low calcium intake, gonadal dysfunction, male gender, Caucasian race and higher doses of antimetabolites ${ }^{[4,5,18]}$. Previous studies have had small patient sizes, shorter follow-up and a mix of patient groups or therapies provided. In the one comparable study of consistently treated patients, 30 of 141 patients had low BMD which is greater than one would see in the general population and similar to our results ${ }^{[4]}$.

Our results do not demonstrate any consistent abnormalities of bone metabolism. Therefore it is unlikely that any permanent damage is caused by either the treatment or the leukemia itself. This is notably confirmed by the fact that our controls with normal bone mass had received the same treatment. Others have also looked at bone markers in survivors ${ }^{[19-22]}$ and have had the same results of no persisting abnormalities of bone mineral metabolism.

There are some limitations to our study. It was unfortunate that we were not able to obtain accurate results for serum osteocalcin thus we could not evaluate bone formation. When we designed the study, a Z score of $<1$ standard deviations compared to age matched controls defined osteoporosis. This has since been changed to $<2$ standard deviations. However, this would not affect our conclusions as it would mean that even fewer patients had low bone density. It is possible that patients with low BMD may have genetic polymorphisms in the bone mineral metabolism pathway that made their recovery slower than their peers. This is an interesting point that is being looked at in the BONEII study at St. Jude's ${ }^{\text {[23] }}$.

The one notable finding is that low Vitamin D status was observed in $37 \%$ of our subjects equally divided between those with low and normal bone density. Vitamin D levels did not correlate with either the season or lower bone density. Thus low Vitamin D is likely not related to disease or treatment factors but rather a reflection of the cohort's age, lifestyle factors and geographic location, similar to the general population. That there was no correlation between Vitamin D status and PTH levels also suggests that neither are factors in affecting bone density in this population.

Thus, survivors of ALL who have low bone density do so for the same reasons as the general population. Ensuring adequate catch up in bone mass after completion of chemotherapy is the key to ensuring optimal adult bone health. This would include adequate Vitamin D replacement, adequate calcium intake and weight bearing exercise. 


\section{Acknowledgments}

The authors wish to thank the patients who participated in the study. Susan Docherty-Skippen, research assistant at McMaster University conducted that biochemical assays and Maroukh Rafii, research assistant at the Hospital for Sick Children, who performed the statistical analyses.

\section{References}

[1] Surveillance Epidemiology and End Results (SEER). Table 29.1. Age-Adjusted and Age-Specific SEER Cancer Incidence Rates, 2003-2007. [Internet]. [cited 2012 September 7]. Available from:

http://seer.cancer.gov/csr/1975_2007/browse_csr.php?section=29\&page=sect_29_table.01.html

[2] Canadian Cancer Society. Cancer in Children and Youth (0-19 Years): Table W2; Figure W2. [Internet]. [cited 2012 September 7]. Available from:

http://www.cancer.ca/canada-wide/about\%20cancer/cancer\%20statistics/web\%20only\%20content.aspx?sc_lang=en

[3] Halton JM, Hay J, Furlong W. Bone mineral density in children following treatment for acute lymphoblastic leukemia (ALL). Proceedings of the 6th International Conference on Long-Term Complications of Treatment and Adolescents for Cancer. 2000: 41A\#84.

[4] Kaste SC, Jones-Wallace D, Rose SR, et al. Bone mineral decrements in survivors of childhood acute lymphoblastic leukemia: frequency of occurrence and risk factors for their development. Leukemia. 2001; 15(5):728-34. PMid:11368432 http://dx.doi.org/10.1038/sj.leu.2402078

[5] van der Sluis I, van den Heuvel-Eibrink MM, Hahlen K, et al. Bone mineral density, body composition, and height in long-term survivors of acute lymphoblastic leukemia in childhood. Med Pediatr Oncol. 2000; 35: 415-20. http://dx.doi.org/10.1002/1096-911X(20001001)35:4<415::AID-MPO4>3.0.CO;2-9

[6] Mandel K, Atkinson S, Barr RD, et al. Skeletal morbidity in childhood acute lymphoblastic leukemia. J Clin Oncol. 2004; 22: 1215-21. PMid:15051768 http://dx.doi.org/10.1200/JCO.2004.04.199

[7] Pencharz P. Body composition and growth. In: Walker A, ed. Nutrition in Pediatrics: Basic Science and Clinical Application Little Brown \& Co, 1985; 77-85.

[8] Atkinson SA, Halton J, Hay J, Gordon C, Webber CE. Normative values for lumbar spine bone mass in children in relation to age, gender, dietary intake and physical activity, J Bone Miner Res. 1991; 6(1):A196;S132.

[9] Ellis KJ, Abrams SA, Wong WW. Body composition of a young, multiethnic female population. Am J Clin Nutr. 1997 ; 65:724-31. PMid:9062521

[10] Gordon CL, Halton JM, Atkinson SA, et al. The contributions of growth and puberty to peak bone mass. Growth Dev Aging. 1991; 55: 257-62. PMid:1813444

[11] Langlois K, Greene-Finestone L, Little J, et al. Vitamin D status of Canadians as measured in the 2007 to 2009 Canadian Health Measures Survey. Health Rep. 2010; 21:47-55. PMid:20426226

[12] Halton JM, Atkinson SA, Fraher L, et al. Altered mineral metabolism and bone mass in children during treatment for acute lymphoblastic leukemia. J Bone Miner Res. 1996; 11:1774-83. PMid:8915786 http://dx.doi.org/10.1002/jbmr.5650111122

[13] Arikoski P, Kroger H, Riikonen P, et al. Disturbance in bone turnover in children with a malignancy at completion of chemotherapy. Med Pediatr Oncol 1999; 33: 455-61. http://dx.doi.org/10.1002/(SICI)1096-911X(199911)33:5<455::AID-MPO4>3.0.CO;2-3

[14] Athanassiadou F, Tragiannidis A, Rousso I, et al. Evaluation of bone metabolism in children with acute lymphoblastic leukemia after induction chemotherapy treatment. Pediatr Hematol Oncol 2005; 22(4):285-9. PMid:16020115 http://dx.doi.org/10.1080/08880010590935176

[15] Halton JM, Atkinson SA, Fraher L, et al. Mineral homeostasis and bone mass at diagnosis in children with acute lymphoblastic leukemia. J Pediatr 1995; 126:557-64. http://dx.doi.org/10.1016/S0022-3476(95)70349-7

[16] Henderson RC, Madsen CD, Davis C et al. Longitudinal evaluation of bone mineral density in children receiving chemotherapy. J Pediatr Hematol Oncol 1998; 20:322-26. PMid:9703005 http://dx.doi.org/10.1097/00043426-199807000-00008

[17] Kaushik A, Bansal D, Khandelwal N, et al. Changes in bone mineral density during therapy in childhood acute lymphoblastic leukemia. Indian Pediatr. 2009; 46:245-48. PMid:19213989

[18] Kelly KM, Thornton JC, Hughes D, et al. Total body bone measurements: a cross-sectional study in children with acute lymphoblastic leukemia during and following completion of therapy. Pediatr Blood Cancer. 2009; 52:33-38. PMid:18816694 http://dx.doi.org/10.1002/pbc.21760 
[19] Alikasifoglu A, Yetgin S, Cetin M, et al. Bone mineral density and serum bone turnover markers in survivors of childhood acute lymphoblastic leukemia: comparison of megadose methylprednisolone and conventional-dose prednisolone treatments. Am J Hematol. 2005; 80(2):113-8. PMid:16184587 http://dx.doi.org/10.1002/ajh.20438

[20] Hoorweg-Nijman JJ, Kardos G, Roos JC, et al. Bone mineral density and markers of bone turnover in young adult survivors of childhood lymphoblastic leukaemia. Clin Endocrinol. 1999; 50(2):237-44. http://dx.doi.org/10.1046/j.1365-2265.1999.00654.x

[21] Jarfelt M, Fors H, Lannering B, et al. Bone mineral density and bone turnover in young adult survivors of childhood acute lymphoblastic leukaemia. Euro J Endocrinol. 2006; 154(2):303-9. PMid:16452545 http://dx.doi.org/10.1530/eje.1.02092

[22] Marinovic D, Dorgeret S, Lescoeur B, et al. Improvement in bone mineral density and body composition in survivors of childhood acute lymphoblastic leukemia: a 1-year prospective study. Pediatrics. 2005; 116(1):e102-8. PMid:15995009 http://dx.doi.org/10.1542/peds.2004-1838

[23] Rai SN, Hudson MM, McCammon E, et al. Implementing an intervention to improve bone mineral density in survivors of childhood acute lymphoblastic leukemia: BONEII, a prospective placebo-controlled double-blind randomized interventional longitudinal study design. Contemp Clin Trial. 2008; 29(5):711-9. PMid:18586578 http://dx.doi.org/10.1016/j.cct.2008.05.002 